\title{
Context Classification during Blood Pressure Self-Measurement using the Sensor Seat and the Audio Classification Device
}

\author{
Stefan Wagner, Niels Holm Rasmussen, Peter Ahrendt, \\ Thomas S. Toftegaard \\ Department of Engineering \\ Aarhus University \\ Aarhus, Denmark \\ \{sw, 20062248, pah, tst $\} @$ iha.dk
}

\author{
Olav W. Bertelsen \\ Department of Computer Science \\ Aarhus University \\ Aarhus, Denmark \\ olavb@cs.au.dk
}

\begin{abstract}
Blood pressure self-measurement (BPSM) requires the patient to follow a range of recommendations. Patients must remain silent during measurements, be seated correctly with back support and legs uncrossed, and must have rested at least 5 minutes prior to taking the measurement. Current blood pressure (BP) devices cannot verify whether the patient has followed these recommendations or not. As a result, the data quality of BP measurements could be biased. We present a proofof-concept demonstration prototype that uses audio context classification for detecting speech during the measurement process, as well as a sensor seat for measuring patient posture and activity before and during the BPSM process.
\end{abstract}

Keywords-component; blood pressure self-measurement, context classification, pervasive healthcare, data quality

\section{INTRODUCTION}

Blood pressure self-measurement (BPSM) is important in the diagnosis and monitoring of several chronic patient groups [1-3] and the official recommendations for obtaining the measurements must be followed [4-6]. The use of information technology for obtaining BPSM has been investigated in several studies without investigating whether patients are following the recommendations [7, 8]. As current state-of-theart BP devices are not capable of sensing incorrect usage [9] and only measurements following the recommendations are considered reliable [1-3], it may be argued that the quality of data from the reported studies $[7,8]$ could be indeterminate and the clinical use of such systems could lead to potential over or under medication $[1,8,10]$.

This extended abstract presents a proof-of-concept prototype that demonstrates how user-context during BPSM can be registered in order to detect contextual-bias. The prototype demonstrates several practical examples from our ongoing investigation of context-aware technologies for increased data quality and patient adherence of pervasive healthcare systems [11-13].

\section{METHODS \& MATERIALS}

\section{A. System Overview}

The system consists of a standard wireless blood pressure device (BPD) as used in current clinical praxis, a sensor seat (SS) for registering user-posture and rest-time, as well as a tablet computer (TC) that integrates the BPD and SS, provides a user interface, as well as performs audio classification of the data obtained (see Figure 1).

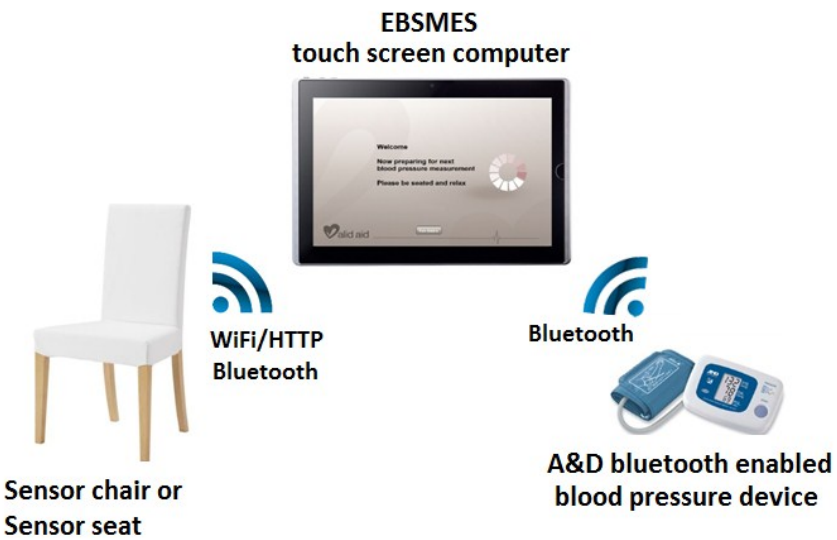

Figure 1. When a test-subject is seated the system monitors activity and posture and starts recording audio data. When a BP measurement is received the audio data is processed and classified as speech or silence.

\section{B. Componets Used}

The TC device (used: ASUS Eee Slate EP121, ASUSTeK Computer Inc., Taiwan) is running the experimental BPSM Evaluation Solution (EBSMES) that communicates with the BPD and SS devices, as well as provides audio context classification capabilities. The audio classification algorithm is based on the Artificial Neural Network classifier (ANN) [14]. 
The BPD device is based on the widely used A\&D blood pressure device (used: A\&D Digital Blood Pressure Monitor UA-767PBT, A\&D Company Limited, Japan) which can communicate wirelessly using Bluetooth.

The Seat Sensor (SS) is based on the TinyOS Shimmer platform (used: Shimmer Wireless Sensor, Shimmer Research, Ireland) using two external piezoresistive sensors (FlexiForce, Tekscan Inc., US) for sensing leg placement. Further sensors have been implemented, including temperature, movement, and noise level. However, these are not presented in this extended abstract and demonstration prototype.

\section{Demonstraiton Goals}

We wish to demonstrate how context classification can be used to tag healthcare data with contextual data. This is useful for providing an improved understanding of healthcare measurements in the unsupervised setting, and could improve the validity of unsupervised measurements.

The prototype we wish to demonstrate illustrates how a context-aware pervasive healthcare system can capture and register incorrect usage of healthcare devices. The prototype demonstrates how context such as incorrect posture, talking during measurement, as well as sitting with legs crossed can be identified and registered in an adherence model.

We utilize either the sensor chair [13] or the sensor seat and associated software components in order to register testsubjects getting seated, and later standing up. This is used to determine when to start recording audio data, and when a measurement session should be considered complete. Also, the sensor seat will provide information on patient rest time and whether legs were crossed during measurement.

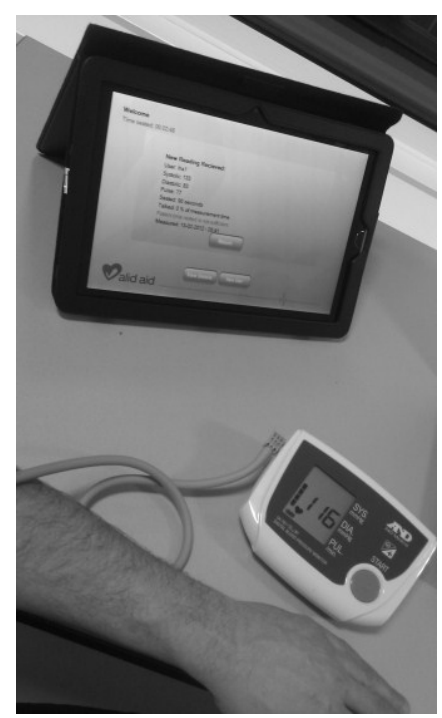

Figure 2. The touch screen computer running EBSMES (above) and the A\&D blood pressure device (below).

As the sensor chair is not feasible for mobile use, we have devised the sensor seat, a limited but mobile platform that is easy to transport, and can be placed in a chair or a sofa.
The user interface is constructed to also allow the patient autonomous control over the solution. Also, all BP measurement data and contextual meta-data are collected in a structured format using extensible markup language (XML), and all audio data are stored as raw PCM files for later review.

\section{ACKNOWLEDGMENTS}

Thanks to industrial designer Anders Bech Christensen, for graphical and conceptual design of the user interface software, as well as work on the seat sensor.

\section{REFERENCES}

[1] N.R.C. Campbell and D.W. McKay, "Accurate blood pressure measurement: Why does it matter?", Can.Med.Assoc.J., vol. 161, pp. 277-278, 1999.

[2] T.G. Pickering, Ambulatory monitoring and blood pressure variability, Science Press, 1991, .

[3] S.D. Pierdomenico, M. Di Nicola, A.L. Esposito, R. Di Mascio, E. Ballone, D. Lapenna and F. Cuccurullo, "Prognostic value of different indices of blood pressure variability in hypertensive patients", Am.J.Hypertens., vol. 22, pp. 842-847, Aug. 2009.

[4] T.G. Pickering, J.E. Hall, L.J. Appel, B.E. Falkner, J. Graves, M.N. Hill, D.W. Jones, T. Kurtz, S.G. Sheps and E.J. Roccella, "Recommendations for blood pressure measurement in humans and experimental animals: part 1: blood pressure measurement in humans: a statement for professionals from the Subcommittee of Professional and Public Education of the American Heart Association Council on High Blood Pressure Research", Circulation, vol. 111, pp. 697-716, Feb 8. 2005.

[5] L.E. Bang, K.L. Christensen, K.W. Hansen, K. Skov and N. Wiinberg, "Diagnostisk blodtryksmåling - på døgnbasis, hjemme og i konsultationen ", 2006.

[6] J. Frantz, F. Feihl, B. Waeber and European Society of Hypertension, "Practice guidelines of the European Society of Hypertension for home blood pressure measurement," Rev.Med.Suisse, vol. 6, pp. 1696-1699, Sep 15. 2010.

[7] L. Huniche, B. Dinesen, O. Grann, E. Toft and C. Nielsen, "Empowering patients with COPD using Tele-homecare technology", Stud.Health Technol.Inform., vol. 155, pp. 48-54, 2010.

[8] A. AbuDagga, H.E. Resnick and M. Alwan, "Impact of blood pressure telemonitoring on hypertension outcomes: a literature review", Telemed.J.E.Health., vol. 16, pp. 830-838, Sep. 2010.

[9] S. Wagner, T.S. Toftegaard and O.W. Bertelsen, "Challenges in Blood Pressure Self-Measurement", International Journal of Telemedicine and Applications, vol. 2012, 2012.

[10] T.G. Pickering, N.H. Miller, G. Ogedegbe, L.R. Krakoff, N.T. Artinian, D. Goff, American Heart Association, American Society of Hypertension and Preventive Cardiovascular Nurses Association, "Call to action on use and reimbursement for home blood pressure monitoring: executive summary: a joint scientific statement from the American Heart Association, American Society Of Hypertension, and Preventive Cardiovascular Nurses Association", Hypertension, vol. 52, pp. 1-9, Jul. 2008.

[11] S. Wagner, T.S. Toftegaard and O.W. Bertelsen, "Novel approach for ensuring increased validity in home blood pressure monitoring", in Pervasive Computing Technologies for Healthcare (PervasiveHealth), 2010 4th International Conference on, pp. 1-4, 2010.

[12] S. Wagner, T.S. Toftegaard and O.W. Bertelsen, "Increased Data Quality in Home Blood Pressure Monitoring through Context Awareness", in Pervasive Computing Technologies for Healthcare (PervasiveHealth), 2011 5th International Conference on, pp. 1-4, 2011.

[13] S. Wagner, T. Toftegaard and O. Bertelsen, "Context Assessment during Blood Pressure Self-measurement Utilizing the Sensor Chair", Ambient Intelligence, pp. 295-299, 2011.

[14] C.M. Bishop, Pattern recognition and machine learning, Springer New York, 2006. 